\title{
Syringoma of the Palate-A Rare Presentation
}

\section{Goswami R ${ }^{1}$, Gangwani $A^{2}$}

${ }^{1}$ Dr Reema Goswami, Assistant Professor, Department of E.N.T, ${ }^{2}$ Dr Amar Gangwani, Assistant Professor, Department of Pathology. Both affiliated with Bundelkhand Medical College Sagar, Madhya Pradesh, India.

Address for Correspondence: Dr Reema Goswami, Email: reemadevgoswami@ gmail.com

\begin{abstract}
Syringoma is a benign adenexal neoplasm formed by well differentiated ductal elements. They are tumors of eccrine origin commonly found over upper part of cheek, lower eyelid, axilla, chest, abdomen, penis and vulva. A 40 year male reported in the OPD with an asymptomatic swelling over the hard palate for the past 15 year. The tumor was excised and sent for histopathological examination. Histological examination showed clusters of eccrine ducts lined by doubled layer epithelial cells. Lumen showed keratinous accellular eosinophillic material suggestive of Syringoma. The case of Syringoma is being reported for its unusual presentation over the palate suggesting it should be considered in the differential diagnosis of various swelling of the palate.
\end{abstract}

Key words: Syringoma, eccrine glands, palate.

\section{Introduction}

Syringoma are benign adenexal tumors derived from intraepidermal portion of eccrin sweat glands ${ }^{1}$. They are usually present as skin coloured yellow dermal papules on lower eyelid, cheek axilla, neck and abdomen ${ }^{2}$. There are numerous small minor salivary glands located within the submucosa of the palate and are capable of developing a wide range of conditions ${ }^{3}$.

The most common benign salivary gland tumor of the palate is plemorphic adenoma ${ }^{4,5}$. Some types of salivary gland tumors occur predominantly or more exclusively in minor salivary glands of oral cavity. They include basal cell adenoma, myoepithloma, sialadenoma papelliferum, inverted ductal papilloma, syringoma and polymorphous low grade adenocarcinoma 6. A case of syringoma is being reported for its unusual presentation over the hard palate.

\section{Case report}

A 40 year old male presented in the ENT OPD with a swelling over the palate for 15 years. The swelling was insidious in onset, very gradually increasing in size. There was no pain associated with the swelling and no history of odynophagia.

Manuscript received: $16^{\text {th }}$ Aug 2013

Reviewed: $16^{\text {th }}$ Sept 2013

Author Corrected: $29^{\text {th }}$ Sep 2013

Accepted for Publication: $18^{\text {th }}$ Nov 2013
On examination a well circumscribed swelling was present over the right side of hard palate, over the posterior one third, approximately $2 * 2.5 \mathrm{~cm}$. The mucosa over the swelling had a bluish hue. On palpation the swelling was smooth, firm, not fixed and non tender. Dental examination was normal. Anterior rhinoscopy showed no abnormality. There was no cervical lymphadenopathy. Systemic examination was normal. Routine blood investigations were in the normal limit. XRay PNS was normal.

Surgical exploration was performed by intraoral approach. An incision was made over the swelling. The tumor was separated from underlying tissue by finger dissection and removed. The wound was closed with vicryl sutures. Post operatively antibiotics, anti inflammatory drugs and antiseptic mouth wash were given for seven days.

Gross appearance of the specimen was a well capsulated yellowish white mass about $2 * 2 * 1 \mathrm{~cm}$. Histopathological examination showed clusters of small eccrine ducts lined by double layer epithelial cells with comma extension. Lumen of the ducts showed keratinous acellular eosinophilic material. There were no atypical cells seen in the section. These findings were suggestive of Syringoma.

After surgery, follow up for 6 months showed palatal the defect was completely closed and there were no signs and symptoms of recurrence. 


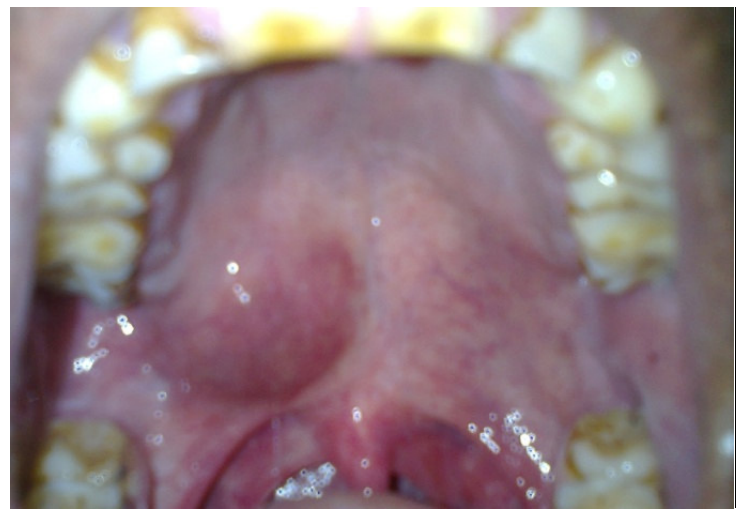

Fig 1: Swelling over the palate

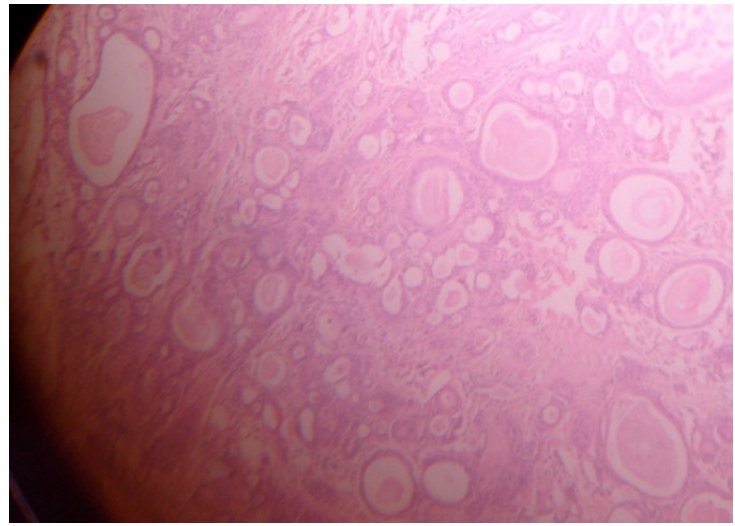

Fig 3: Histopathology slide (H\&E x 10) shows eccrine ducts lined double layer epithelial cells with comma extensions.

\section{Discussion}

Syringoma is a benign adnexal neoplasm formed by well differentiated elements. The name 'Syringoma' is derived from the Greek word syrinx which means pipe or tube. The tumors are of eccrine origin commonly found over upper part of cheek, lower eyelid, axilla, chest, abdomen, penis, vulva and dorsum of hand. Based on Friedman and Butlers classification four variants of Syringoma are recogonised that include localized, Generalized, Familial $\&$ form associated with Downs syndrome ${ }^{3-7}$.

Syringomas are skin coloured or yellowish small papulonodular lesions \& usually less than $3 \mathrm{~mm}$ in diameter. Rare cases of giant syringomas have been reported ${ }^{8}$. These tumors are more common in females than males. The age of presentation is puberty but can develop later. Incidence is increased in Downs syndrome ${ }^{7,9}$

Microscipially the tumors are formed by clusters of small ducts lined by epithelium of two cells thickness, occasionally with comma shaped extensions. The ultrastructural and immune histochemical findings

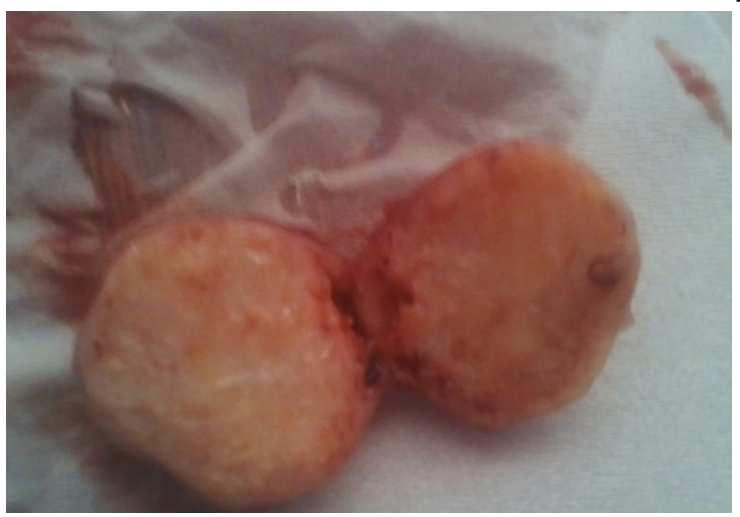

Fig 2: Gross appearance of excised mass

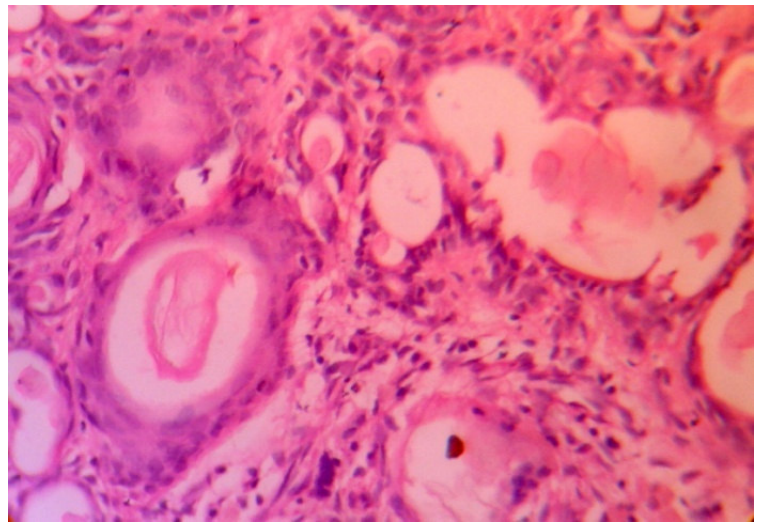

Fig 4: Histopathology slide (H\&E x 40) shows ducts lined By epithelial cells. Lumen of the duct shows acellular eosinophilic material

indicate these lesions are of eccrine rather than aporcrine nature ${ }^{1}$. Syringomatous tumors of minor gland origin have been reported by Johnston CA and Toker $\mathrm{C}^{10}$. An intraoral adenocarcinoma of minor salivary gland showing syringomatous changes has been reported by Bondi $\mathrm{R}$ and Urso C. This represents a rare variant of salivary gland adenocarcinoma $^{11}$.

The various modalities of treatment are surgical excision

with primary suturing, surgical excision with secondary intention healing, electrocautery and electrodissection with curettage. With laser treatment like $\mathrm{CO}_{2}, \mathrm{YAG}$, and fractional $\mathrm{CO}_{2}$ laser application, the tumor can be removed with minimal scarring ${ }^{12,13}$.

\section{Conclusion}

The histological diagnosis of syringoma in the case reported suggests that in the evaluation of patients with palatal swellings syringoma should be considered in the differential diagnosis. 


\section{References}

1. Hashimoto K, Gross BG, Lever WF. Syringoma, Histochemical and electron microscopic studies. J Invest Dermatol 1966; 46:150-166.

2. Shrivastava D, Taylor R.S. Appendage Tumors \& Hamartomas In skin, IN: Lowell A. Goldsmith Stephen I. Katz Barbara A .Gilchrest, Amy S. Paler, David J. Leffell, Klaus Wolff in, editors. Fitzpatrick's Dermatology in General Medicine $8^{\text {th }}$ edition. USA: Mc Graw Hill; 2012. p. $1337-1362$.

3. Dardick I, Van Nostrand AW. Morphogenes of Salivary gland tumor. A prerequisite to improving classification. Pathol Annu 1987;22:1-53.

4. Ellis GL, Auclair PL, Atlas of tumor pathology: Tumors of Salivary gland. Washington DC Armed forces Instutute of Pathology; 1996.

5. Pilch BZ. Head and Neck Surgical Pathology. $1^{\text {st }}$ ed. Philadelphia PA: Lippincott, Williams and Wilkins; 2000.

6. Rosai and Ackerman's Surgical Pathology. $9^{\text {th }}$ edition. St Louis Missouri. Mosby, 2004.
7. Friedman SJ, Butler DF. Syringoma Presenting as milia. J Am Acad Dermatol 1987;16:310-4.

8. Blasdale C. Mclelland . Solitary vulval Syringoma. $\mathrm{Br}$ J. Dermatol 1999 Aug; 141 (2);374-5.

9. Schepis C, Sirangusa M, Palazzo R, Ragusa RM, MassiG, FabrizeG. Palpaberal Syringomas and Downs Syndrome. Dermatology 1994:189(3);248-50.

10. Johnston CA,Tocker C.Syringomatous tumor of minor salivary gland origin. Hum pathol 1982 Feb; 13(2): 182-4.

11. Bondi R, Urso C. Syringomatous adenocarinoma of minor salivary Gland Tumori. 1990 June 30; 76(3):286-9.

12. Wang JI, Roening K HH. Jr Treatment of multiple facial syringoma with $\mathrm{CO}_{2}$ laser. Dermatol Surg. 1999;25:136-9.

13. Frazier CC, Camcho AP, Lockecell CJ. The Treatment of eruptive syringoma in African American patient with trichloroacetic and $\mathrm{CO}_{2}$ laser. Dermotol Surg 2001;27:489.

\section{How to cite this article?}

Goswami R, Gangwani A. Syringoma of the Palate-A Rare Presentation. Int J Med Res Rev 2013;1(5):267-269. doi:10.17511/ijmrr.2013.i5.10. 